\title{
Высоковольтная деградация электродов, обусловленная электрохимической инжекцией в жидких диэлектриках
}

\author{
А. И. Жакин ${ }^{*}$, А. Е. Кузько ${ }^{*}$ \\ Федеральное государственное бюджетное образовательное учреждение \\ высшего образования «Юго-Западный государственный университет», \\ 2. Курск, 305040, Россия \\ "e-mail: zhakin@mail.ru, ${ }^{* *}$ e-mail: kuzko@mail.ru \\ Поступила в редакцию 21.04.2021 \\ После доработки 21.05.2021 \\ Принята к публикации 24.05.2021
}

\begin{abstract}
Приведены результаты экспериментальных исследований деградации электродов, обусловленной электрохимическими реакциями под действием высоковольтных полей. Исследованы технические углеводородные и полиметилсилоксановые (ПМС) жидкости, их растворы с йодом $\left(\mathrm{I}_{2}\right)$ при химически активных $(\mathrm{Cu})$ и индифферентных (Тi) электродах. Показано, что в углеводородах меди электроды интенсивно взаимодействуют с $\mathrm{I}_{2}$, причем катодная деградация более интенсивная, чем анодная. Титановые электроды не деградируют, но на них в углеводородах происходит физическая адсорбция $\mathrm{I}_{2}$, а в ПМС на них образуется полимерная пленка. Изучена кинетика деградации во времени.
\end{abstract}

Ключевые слова: ион, диполь, поляризация, диэлектрическая проницаемость, жидкий диэлектрик, электрическое поле, напряженность, электрический ток, электрохимическая реакция, инжекция зарядов, деградация электродов

\section{УДК 532.5: 537.58:537.84:538.3: 541.24 \\ https://doi.org/10.52577/eom.2021.57.6.36 ВВЕДЕНИЕ}

Высокоомные жидкости с проводимостью менее $10^{-11} \mathrm{Cm} / \mathrm{M}$ принято называть жидкими диэлектриками (ЖД) [1-3], а при проводимости порядка $10^{-7} \mathrm{Cm} / \mathrm{M}$ - слабыми электролитами [3-7]. Отличие этих терминов обусловлено тем, что слабые электролиты не выдерживают высоковольтные поля, тогда как в ЖД пробойные напряженности достигают десятков кB/см. Тем не менее по механизму электропроводности эти жидкости имеют много общего. Именно это обстоятельство положено в основу современной теории электропроводности ЖД [8-14], в которых движение ионов происходит не только за счет их миграции в электрическом поле, но и за счет конвекции, что приводит к развитию электрогидродинамических (ЭГД) течений [15-20]. Взаимодействие ионов вызывает так называемую аномальную электропроводность [7], при которой появляются ионные пары и ионные комплексы [7], образующие довольно сложные зарядовые структуры в приэлектродных областях [13]. Если в вопросе об объемной электропроводности ЖД сложились устойчивые представления [11], то инжекционная проводимость, которая обусловливает деградацию, изучена фрагментарно [12] и не стала объектом широкого изучения.

В данной работе исследуется электрохимическая деградация электродов.
Анализируются неполярные ЖД (трансформаторное масло - ТМ, керосин и полиметилсилоксановые - ПМС - жидкости) при химически активных (Cu) и индифферентных (Ti) электродах. Используются как традиционные методы - измерения вольт-амперных (BAX) и ампер-временных характеристик (ABX), так и высоколокальные методы исследования поверхности (атомно-силовая микроскопия - ACM, конфокальная микроскопия, спектроскопия комбинационного рассеяния - КР и др.), позволяющие детализировать механизмы инжекции зарядов.

\section{ОБЩАЯ ХАРАКТЕРИСТИКА ЭЛЕКТРОПРО- ВОДНОСТИ ЖИДКИХ ДИЭЛЕКТРИКОВ}

\section{Объемная ионизация}

В углеводородах и их соединениях электрохимическая активность определяется группами стильбенов $(-\mathrm{CH}=\mathrm{CH}-)$, толанов $(-\mathrm{C} \equiv \mathrm{C}-)$ и др. Активация усиливается при наличии электроноакцепторных групп, например в ароматических углеводородах типа $\mathrm{R}-\mathrm{B}$, где $\mathrm{R}$ - бензольное кольцо; В - атом галогена (йод, бром и др.) или нитрогруппа $\mathrm{NO}_{2}$ в нитробензоле. Так как молекулы В обладают высокой электроотрицательностью (способностью присоединять электроны), то объемную ионизацию жидкого диэлектрика можно схематически представить в виде: 
Таблица 1. Физические свойства некоторых технических неполярных жидких диэлектриков

\begin{tabular}{|c|c|c|c|c|c|c|c|}
\hline Жидкость & $\begin{array}{c}\rho, \\
\Gamma \cdot \mathrm{cM}^{-3}\end{array}$ & $\begin{array}{l}\eta, \text { пз } \\
20^{\circ} \mathrm{C}\end{array}$ & $\begin{array}{l}t_{\text {кип }}, \\
{ }^{\circ} \mathrm{C}\end{array}$ & $\varepsilon$ & $\operatorname{tg} \varphi$ & $\begin{array}{l}\sigma, 10^{-14} \\
\mathrm{CM} / \mathrm{cm}\end{array}$ & $\begin{array}{c}E_{\text {пр }} \\
\text { кВ/см }\end{array}$ \\
\hline Нефтяное ТМ, $\mathrm{C}_{\mathrm{n}} \mathrm{H}_{2 \mathrm{n}}$ & 0,89 & $0,2-0,8$ & - & 2,2 & 0,003 & $\sim 1$ & 15 \\
\hline $\begin{array}{c}\text { Нефтяное конденсаторное } \\
\text { масло, } \mathrm{C}_{\mathrm{n}} \mathrm{H}_{2 \mathrm{n}} \\
\end{array}$ & 0,87 & 0,8 & - & 2,0 & $5 \times 10^{-4}$ & $\sim 0,1$ & 20 \\
\hline $\begin{array}{c}\text { Полидиметилсилоксаны } \\
-\left[-0-\mathrm{Si}-\left(\mathrm{CH}_{3}\right)_{2}\right]_{n}- \\
\text { Полидиэтилсилоксаны } \\
-\left[-0-\mathrm{Si}-\left(\mathrm{C}_{2} \mathrm{H}_{5}\right)_{2}\right]_{n}-\end{array}$ & $0,76-0,97$ & $0,6-300$ & $100-450$ & 2,8 & 0,002 & $\sim 1$ & 20 \\
\hline $\begin{array}{c}\text { Фторорганические } \\
\mathrm{C}_{8}-\mathrm{F}_{16}-\mathrm{O} \text { и др. }\end{array}$ & 1,84 & 0,01 & 101 & 1,7 & $5 \times 10^{-4}$ & $\sim 0,1$ & 14 \\
\hline
\end{tabular}

Обозначения: $t_{\text {кип }}-$ температура кипения; $E_{\text {пр }}-$ пробойная напряженность.

$$
\mathrm{A}+\mathrm{B} \leftrightarrow \mathrm{A} \cdot \mathrm{B} \leftrightarrow \mathrm{A}^{+} \cdot \mathrm{B}^{-} \leftrightarrow \mathrm{A}^{+} \mathrm{B}^{-} \leftarrow \frac{k_{d}}{\alpha_{11}} \rightarrow \mathrm{A}^{+}+\mathrm{B}^{-}
$$

Здесь А, В - молекулы несущей жидкости (жидкого диэлектрика) и электроноакцептора; A.B - молекулярный комплекс; $\mathrm{A}^{+} \cdot \mathrm{B}^{-}-$контактная ионная пара; $\mathrm{A}^{+} \mathrm{B}^{-}$- рыхлая ионная пара; $\mathrm{A}^{+}, \mathrm{B}^{-}$- свободные ионы, обусловливающие проводимость жидкого диэлектрика; $k_{d}$ - константа скорости диссоциации ионных пар $\mathrm{A}^{+} \mathrm{B}^{-} ; \quad \alpha_{11}-$ коэффициент рекомбинации моноионов $\mathrm{A}^{+}, \mathrm{B}^{-}$. Такой механизм электропроводности в инженерных приложениях часто называют примесным, а в научной литературе диссоциационным.

Рассмотрим характеристики неполярных ЖД как наиболее перспективных в ЭГД приложениях. Такие ЖД имеют близкие значения по плотности $\rho$, диэлектрической проницаемости $\varepsilon$ и омической проводимости $\sigma$, но существенно отличаются по теплофизическим и электрохимическим свойствам (табл. 1). Так, в ТМ при отсутствии кислот или коллоидных соединений типа уксусной кислоты или нафтената железа электролиз незначительный [21], однако имеет место окисление ТМ (так называемое старение) при доступе воздуха, контакте с металлами ( $\mathrm{Cu}, \mathrm{Fe}, \mathrm{Pb}$ и др.) или воздействии света [22-25]. В то же время как технические охлаждающие жидкости трансформаторные масла позволяют изменять электрофизические характеристики (электро- и теплопроводность, вязкость, пробивное напряжение, удельное сопротивление и др.) добавлением в них в оптимальных концентрациях нановключений (гибридного $\mathrm{SiO}_{2}$ - графена, многостенных и функционализированных углеродных нанотрубок - УНТ, наночастиц $\mathrm{Al}_{2} \mathrm{O}_{3}$ и др.) [26-29]. На электрофизические свойства ЭГД систем оказывает влияние модификация поверхности электродов, например, магнетронное напыление диоксида титана $\left(\mathrm{TiO}_{2}\right)$ увеличивает пробивное напряжение пропилен-карбоната [30], химическое травление электродов и электрофоретическое осаждение однослойных углеродных нанотрубок (ОСУНТ) уменьшает пороговое значение напряжения для инжекции заряда [31].

Фтор и кремнийорганические жидкости отличаются высокой химической инертностью, сравнительно высокой стойкостью при нагреве, а также высокими значениями пробивного напряжения (табл. 1) [32]. Они не растворяются в спиртах и ацетоне и не взаимодействуют с металлами и большинством органических пластмасс и резин. В них растворяются ароматические углеводороды, $\mathrm{CCl}_{4}$, смесь спирта с бензолом. Однако электрохимические свойства в высоковольтных полях изучены недостаточно, поэтому в дальнейшем этому будет уделено особое внимание (см. ниже).

\section{Контактная ионизацчия}

Второй тип электропроводности обусловлен контактными процессами на поверхностях электродов. Эти процессы называют инжекционными. В сверхсильных полях порядка $100 \mathrm{MB} / \mathrm{cm}$ и выше развивается холодная инжекция электронов с поверхности катода, а в средних высоковольтных полях порядка 20 кВ/см на электродах любой полярности электрохимическая инжекция, которая обусловливает ЭГД эффекты.

В ТМ наличие кислотных следов в жидкости определяют по выделению водорода за счет восстановительной реакции:

$$
\text { на катоде: } \mathrm{R}^{-} \mathrm{H}^{+}+e^{-}(M) \rightarrow \mathrm{R}^{-}+\mathrm{H} \text {, }
$$

где $\mathrm{R}^{-}$обозначает кислотный остаток. Например, при наличии в ТМ эмульсионной воды и ледяной уксусной кислоты в поле с напряженностью порядка 50 кВ/см на электродах выделяются водород $\mathrm{H}_{2}$ и углекислый газ $\mathrm{CO}_{2}$ [21]. Отметим, что в истинном растворе воды в ТМ авторы [21] выделение водорода не наблюдали.

Так как йод растворяется в неполярных углеводородах молекулярно, то в силу высокого сродства йода к электрону возможна электрохимическая инжекция отрицательных ионов: 


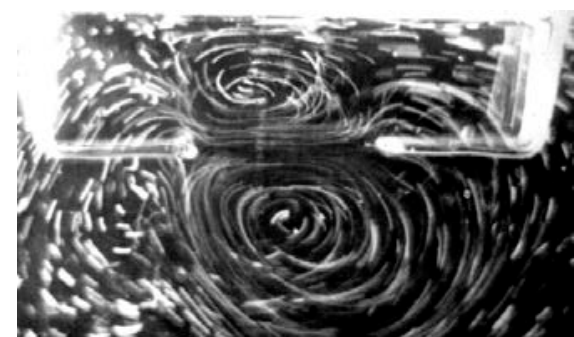

(a)

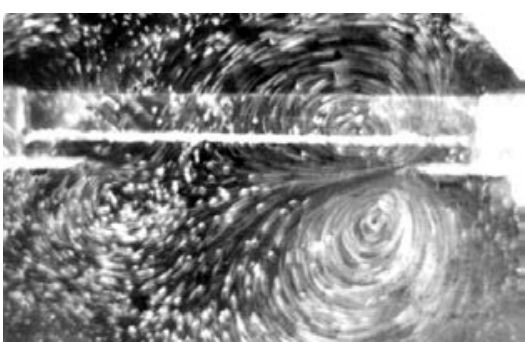

(б)

Рис. 1. ЭГД-течения в симметричных системах электродов в растворах трансформаторного масла с йодом [15]: (а) - система двух параллельных проволочек; (б) - система электродов лезвие-лезвие. Во всех случаях течение направлено от отрицательного электрода.

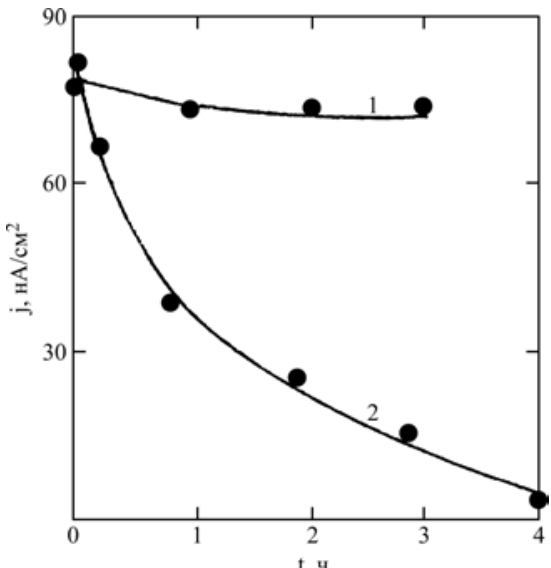

(a)

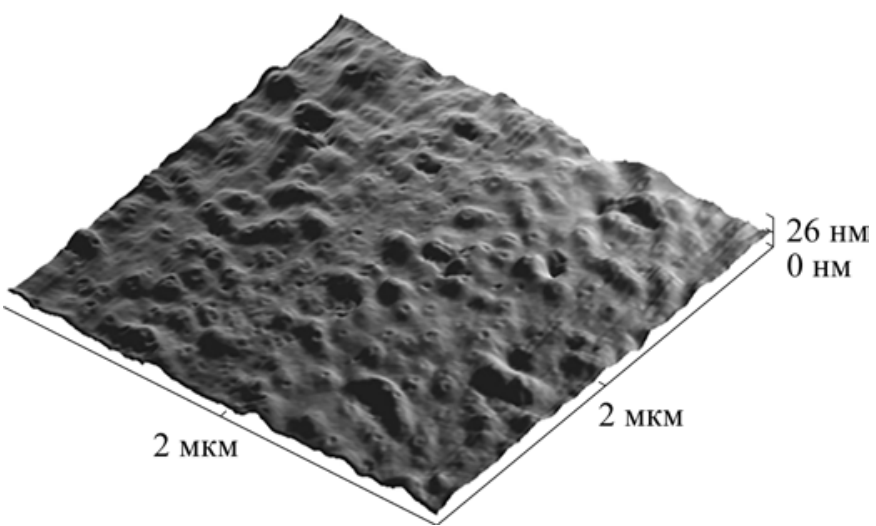

(б)

Рис. 2. Ампер-временные характеристики плоской ячейки насыщенного раствора $\mathrm{TM}+\mathrm{I}_{2}$ (a). Проводимости чистого TM $10^{-14} \mathrm{Cm} / \mathrm{cm}$, раствора $10^{-13} \mathrm{Cm} / \mathrm{cm}$. Напряженность поля 7,3 кВ/см. Кривая 1 - Ті электроды; 2 - Сu электроды. ACM 3D изображение поверхности меди, отполированное с качеством 20 нм (б).

$$
\text { на катоде: } \mathrm{I}_{2}+e^{-}(M) \rightarrow \mathrm{I}_{2}^{-},
$$

при отсутствии или весьма незначительной инжекции зарядов на аноде. Доказательство существования реакции типа (3) можно получить гидродинамическим методом, фиксируя ЭГД-течения от электродов. Так, при симметричных электродных системах типа две параллельные проволочки либо лезвие-лезвие течение в растворе ТМ с молекулярным йодом всегда направлено от катода, а вблизи анода течение не формируется (рис. 1) [15].

Процесс электрохимической инжекции можно схематически представить в виде:

$$
\begin{aligned}
& \mathrm{R}_{1}=\mathrm{R}_{2}-\mathrm{B}+n e^{-} \stackrel{k_{\text {ок }}}{\rightarrow} \\
& \mathrm{X}^{-n}+\text { продукты, }
\end{aligned}
$$

где $\mathrm{X}^{-n}$ - электроотрицательная группа с захваченным с поверхности металла электроном $e^{-}$в ходе электрохимического акта; $k_{\text {ок }}-$ константа скорости электрохимической реакции; $n$ - целое число.

Важным фактором электрохимического процесса являются материал электрода и его поверхностная структура. Известно, что любой металл обладает высокой химической активностью, а инертность того или иного металла определяется оксидной пленкой на его поверхности. Плотные оксидные пленки, образующиеся на поверхностях $\mathrm{Au}, \mathrm{Ti}, \mathrm{Pt}$ и др. металлов, а также специальных сплавов, делают их инертными по отношению к окислению даже в водной среде, но те же оксидные пленки часто являются катализаторами в химических и электрохимических реакциях. Поэтому не удивительно, что при Ті электродах электрический ток, а следовательно, ЭГД течение в растворах трансформаторного масла с йодом $\left(\mathrm{TM}+\mathrm{I}_{2}\right)$ затухают значительно медленнее, чем при $\mathrm{Cu}$ электродах ([8] и рис. 2а). Реальная поверхность любого, даже хорошо отполированного электрода шероховата (рис. 2б), а с учетом оксидной пленки и кристаллической структуры металла имеет дефекты.

\section{Структура приэлектродной области}

Таким образом, ионы проводимости в ЖД формируются за счет двух процессов: диссоциационного (1) и инжекционного (4). Причем примесные $\mathrm{A}^{+}$и инжектируемые $\mathrm{X}^{-n}$ ионы рекомбинируют с образованием ионных комплексов $\mathrm{A}^{+} \mathrm{X}^{-\mathrm{n}}$, что приводит к довольно сложной приэлектродной структуре. На рис. 3 изображена структура распределения ионных компонент и напряженности электрического поля в приэлектродной области при слабой инжекции при $n=1$ [12]. Видно, что инжекти- 


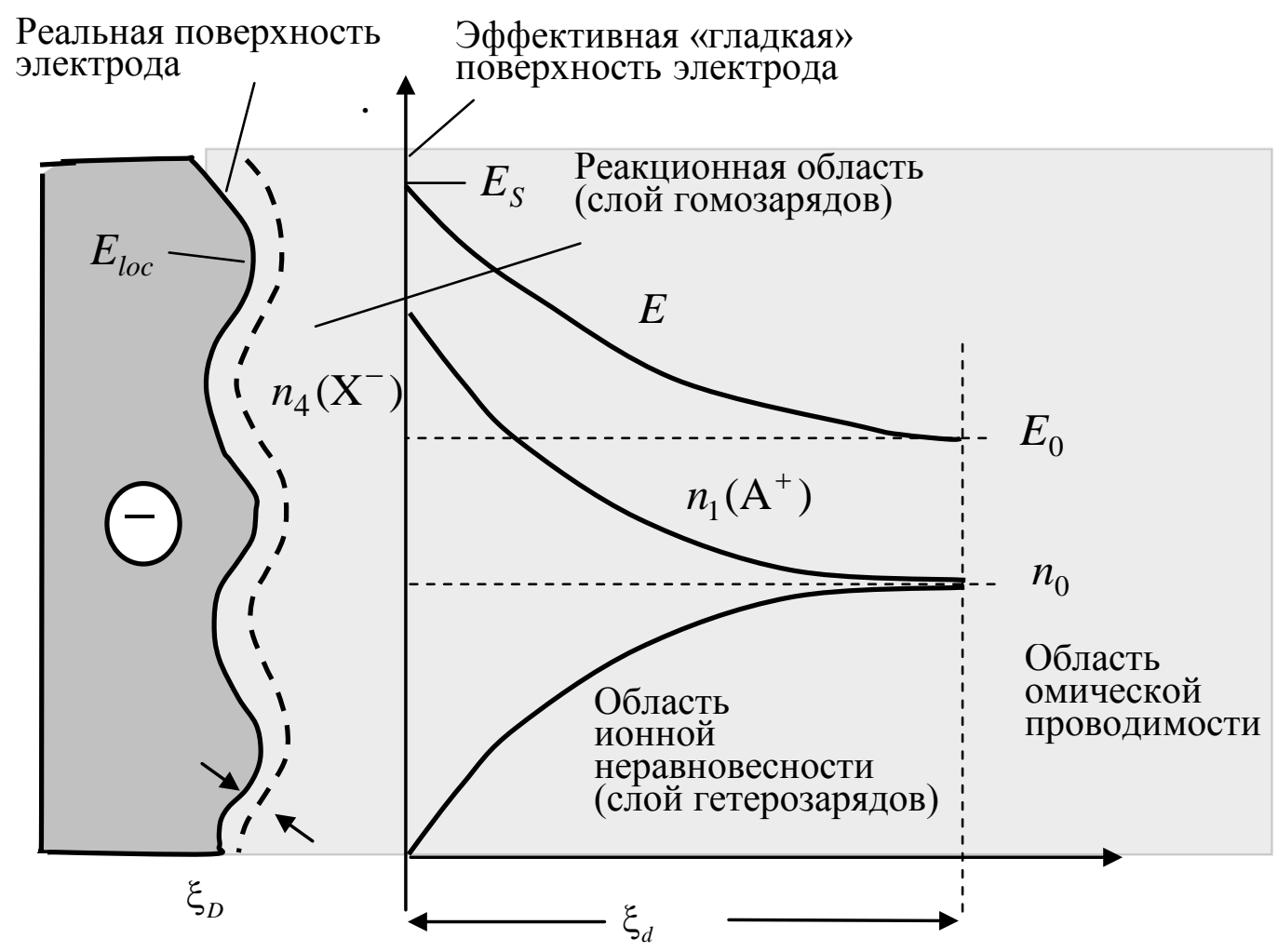

Рис. 3. Ионная структура приэлектродной области в ЖД.

руемые ионы находятся в реакционной области, в которой происходят электрохимические реакции и рекомбинация ионов $\mathrm{X}^{-}$и $\mathrm{A}^{+}$. За реакционной областью находятся область ионной неравновесности, в которой реакция $\mathrm{A}^{+} \mathrm{B}^{-} \leftrightarrow \mathrm{A}^{+}+\mathrm{B}^{-}$сдвигается вправо, и, наконец, область омической проводимости, в которой реакция $\mathrm{A}^{+} \mathrm{B}^{-} \leftrightarrow \mathrm{A}^{+}+\mathrm{B}^{-}$находится в равновесии. Важно отметить, что электрохимические реакции интенсивнее всего происходят на микровыступах или дислокационных сколах на поверхности электрода, где локальная напряженность поля $E_{\text {loc }}$ значительно больше средней напряженности $E_{S}$, вычисляемой на расстоянии от шероховатого электрода порядка 10 калибров размера шероховатости $E_{l o c}=\beta E_{S}$, где $\beta-$ коэффициент локального усиления электрического поля на шероховатости, имеющий порядок 100-10 ${ }^{3}$ (см. [12] и ссылки в этой работе). Вблизи электрода повышается концентрация зарядов полярности, противоположной полярности электродов (гетерозарядов), а концентрация примесных зарядов полярности электрода (гомозарядов) уменьшается. Это приводит к тому, что напряженность электрического поля вблизи электрода возрастает до среднего значения $E_{S}$, а по мере приближения к шероховатому электроду становится неоднородной, резко усиливаясь на микронеоднородностях до величин $E_{l o c}$.
Описанная ионная приэлектродная структура имеет довольно прозрачное физическое объяснение. Действительно, гетерозаряды, мигрируя к электроду, при замедленной разрядке накапливаются на нем, а примесные гомозаряды отталкиваются от электрода. В результате напряженность электрического поля повышается вблизи электрода. Далее в области неоднородности распределения примесных ионов нарушается равновесие реакций диссоциациярекомбинация, поэтому эту область неоднородности называют неравновесным слоем [12], который в дальнейшем будем называть неравновесным ионным слоем (НИС), а его толщину обозначим как $\xi_{d}$. В силу конечности скорости разрядки гетерозарядов на поверхности электрода происходит их накопление в узком диффузионном слое (ДС) толщиной $\xi_{D}$. Обратим внимание, что указанный диффузионный слой не имеет ничего общего с двойным электрическим слоем (ДЭС) в электролитах, так как он обладает совершенно иной природой, обусловленной разными механизмами образования. Так, ДС образуется только за счет накопления зарядов в высоковольтном поле при их конечной скорости разрядки и он существенно неравновесный (имеется ток). Структура ДЭС равновесная (тока нет) и состоит из двух слоев: адсорбционной плотной части зарядов, которые за счет электростатического притяжения формируют вторую диффузионную часть ДЭС толщиной радиуса 
Таблица 2. Характеристики теплоносителей ТМ и ПМС

\begin{tabular}{|c|c|c|c|c|}
\hline Теплоноситель & $t_{\text {пл, }}{ }^{\circ} \mathrm{C}$ & $t_{\text {кип, }}{ }^{\circ} \mathrm{C}$ & $\begin{array}{c}v, \mathrm{MM}^{2} / \mathrm{c} \\
\left(t=20^{\circ} \mathrm{C}\right)\end{array}$ & $\begin{array}{c}v, \mathrm{MM}^{2} / \mathrm{c} \\
\left(t=50^{\circ} \mathrm{C}\right)\end{array}$ \\
\hline $\begin{array}{c}\text { Олигодиметилсилоксаны } \\
\text { (ПМС-50, 100) }\end{array}$ & -64 & $>250$ & $18-105$ & $14-55$ \\
\hline Теплоноситель «Пента-410» & - & 400 & $45-65$ & - \\
\hline Трансформаторное масло & -40 & 135 & 28 & 9 \\
\hline
\end{tabular}

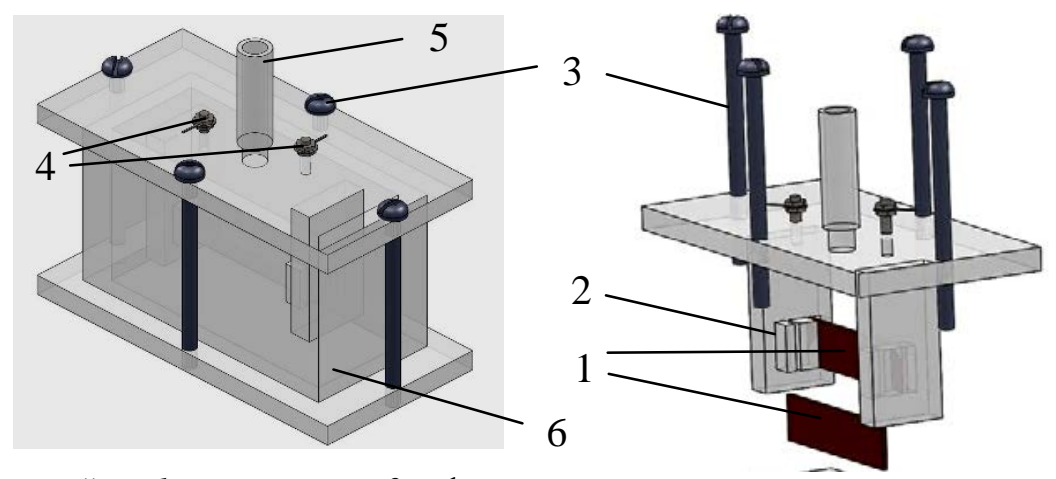

Рис. 4. Измерительная ячейка: 1 - электроды; 2 - фторопластовые держатели с посадочным местом для электрода; 3 - винты крепления; 4 - соединительные клеммы электродов; 5 - трубка для дегазации; 6 - корпус.

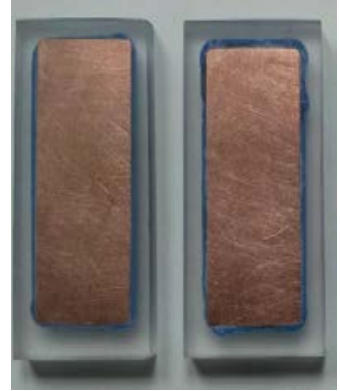

(a)

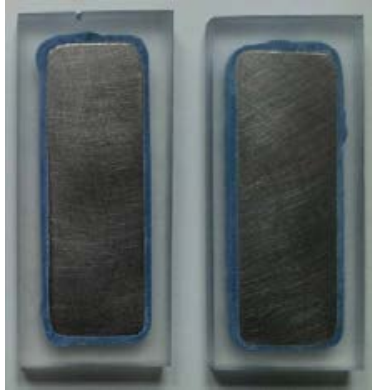

(б)

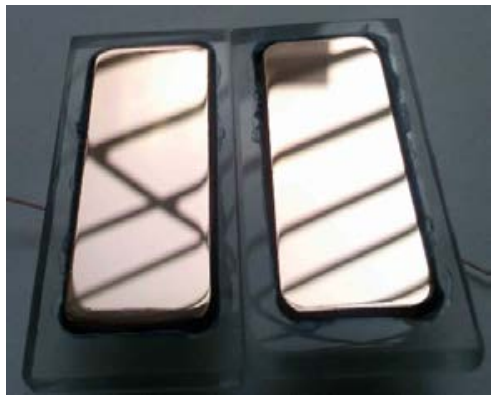

(в)

Рис. 5. Фотографии прямоугольных электродов: (а) медных; (б) титановых; (в) после полировки до качества 20 нм.

Дебая. Причем размер ДС определяется напряженностью внешнего поля $E_{0}$ (см. ниже (7)), тогда как толщина ДЭС зависит только от концентрации электролита и адсорбционных свойств ионов и в ЖД имеет макроскопический размер (порядка нескольких миллиметров). В случае ДЭС электрическое поле по мере удаления от электрода обращается в нуль, тогда как в случае ДС остается высоковольтным даже при наличии ионного равновесия в области омической проводимости.

Итак, за пределами НИС реакция диссоциация-рекомбинация находится в равновесии, то есть $n_{1}=n_{2}=n_{0}$, при этом напряженность электрического поля на границе НИС равна $E_{0}$. В этой области формируется омическая проводимость с постоянным коэффициентом электропроводности:

$$
\sigma=e\left(b_{1}+b_{2}\right) n_{0}, n_{0}=\sqrt{k_{d} N / \alpha_{11}},
$$

где $b_{1}, b_{2}$ - подвижности ионов $\mathrm{A}^{+}, \mathrm{B}^{-}$соответственно; $N$ - концентрация ионных пар $\mathrm{A}^{+} \mathrm{B}^{-}$, а плотность тока $\vec{j}$ линейна по напряжению:

$$
\vec{j}=\sigma \vec{E} .
$$

Вычисления показывают [12], что толщины $\xi_{d}, \xi_{D}$ можно оценить выражениями:

$$
\begin{aligned}
& \xi_{D}=\varphi_{0} / E_{0},\left(\varphi_{0}=k_{B} T / e\right), \\
& \xi_{d}=\varepsilon E_{0} /\left(e n_{0}\right),\left(e n_{0}=\sigma /\left(b_{1}+b_{2}\right),\right.
\end{aligned}
$$

где $k_{B}, T$ - постоянная Больцмана и абсолютная температура соответственно; $\varphi_{0}-$ специфический потенциал. Простые оценки показывают, что при комнатных температурах, проводимостях $\sigma=10^{-12} \mathrm{Cм} / \mathrm{cm}$ и типичных $b_{1} \sim b_{2} \sim 10^{-4} \mathrm{~cm}^{2} /(\mathrm{B} \cdot \mathrm{c})$ при напряженностях поля порядка $E_{0}=1 \mathrm{\kappa B} / \mathrm{cm}$ и диэлектрической проницаемости $\varepsilon=2$ имеют место следующие оценки: $\xi_{D}=260$ нм, $\xi_{d}=0,3$ мм. Видно, что с ростом напряженности электрического поля толщина ДС уменьшается, а толщина НИС, наоборот, увеличивается.

С ростом напряженности электрического поля интенсифицируется электрохимическая инжекция, так что концентрация инжектируемых зарядов возрастает и становится сравнимой с концентрациями примесных ионов. В этом 
случае начинают рекомбинировать не только примесные ионы между собой, но и примесные и инжектируемые ионы. Здесь надо выделять два предельных случая, когда: 1) внешнее поле однородно, как в плоском конденсаторе; 2) поле сильно неоднородно, например при параллельно расположенных тонких проволочках.

В однородных полях в приэлектродной области возникают довольно сложные ионные структуры. Так, при низкой подвижности $b_{i}$ инжектируемых ионов:

$$
b_{i}<<b_{1}, b_{2} \text {, }
$$

в приэлектродной области возможно образование биполярных ионных слоев (БИС) [13]. В сильно неоднородных полях, например при тонких проволочных или острийковых электродах, БИС, как правило, не образуются.

\section{МЕТОДИКА ИЗМЕРЕНИЙ}

Так как для ЭГД приложений важна инжекционная проводимость, при которой происходит деградация электродов, то в данном разделе сосредоточим внимание на изменении их поверхностных структур. Здесь приводятся результаты исследований технических неполярных углеводородных ЖД, которые обладают близкими физико-химическими свойствами, и жаропрочных ПМС жидкостей (табл. 2). Цель исследований - изучить свойства индифферентных (Ti) и химически активных (Cu) электродов по отношению к контактной ионизации.

Ячейка изготовлена из оргстекла проводимостью $\sim 10^{-15} \mathrm{Cм} \cdot \mathrm{M}^{-1}$ с корпусом в виде параллелепипеда, внутренними размерами $56 \times 40 \times 20$ мм $^{3}$ (рис. 4). Плоскопараллельные электроды устанавливались в центре ячейки.

Чтобы предотвратить поверхностную проводимость по стенкам ячейки и крепежным элементам, электроды друг от друга были изолированы отдельными вставками из оргстекла с фторопластовыми держателями. В данные держатели вставлялись прямоугольные электроды размерами $40 \times 16 \times 1,5$ мм $^{3}$ на расстоянии 3,5 мм друг от друга. Для дегазации предусматривались герметизация ячейки и откачка растворенных в ЖД газов форвакуумным насосом до давления 150 Па.

Перед установкой в держатели электроды проходили длительную предподготовку в виде шлифовки и полировки по стандартной методике c помощью однодискового шлифовальнополировального станка Labo-Po12. Для удобства шлифовки и полировки образцы электродов закреплялись с помощью отвержденного компаунда в специальных потаях, сделанных на фрезерном станке в корпусе держателя из оргстекла (рис. 5).

Принципиальная схема установки представлена на рис. 6. Источник питания ИВНР-50 на одном полюсе генерировал отрицательный потенциал относительно земли, другим полюсом была земля. Для измерения токов использовался универсальный вольтметр В-7-78-1, который подключался параллельно эталонному сопротивлению известного номинала (44,4 МОм). Сопротивление ячейки с чистой ПМС-50 составляло $\sim 650$ ГОм.

Ошибка, вносимая эталонным сопротивлением в измерение силы тока, составляла тысячные доли процента. Для «стекания» паразитного заряда с поверхности корпуса киловольтметра, изготовленного из органического стекла, он был оклеен металлической фольгой, которая заземлялась. Для защиты универсального вольтметра от пробоя использовался сконструированный разрядник типа остриеострие. Для исключения поверхностных утечек заряда и вследствие коронного разряда все высоковольтные провода имели фторопластовую изоляцию, а дополнительное сопротивление киловольтметра покрывалось развитой изоляцией из оргстекла. Все несущие высокий потенциал элементы конструкции помещались на предметный столик из оргстекла.

\section{РЕЗУЛЬТАТЫ ИССЛЕДОВАНИЙ}

\section{Токовые характеристики}

Для выбора токовых режимов при исследовании процессов на деградацию электродов проводились измерения вольт-амперных (BAX) и ампер-временных характеристик (ABX). На рис. 7 представлены примеры графиков вольт-амперных характеристик для качественной оценки в системе $\mathrm{Cu}+$ TM. Группа из восьми графиков (обозначение 1) соответствует трансформаторному маслу (ТМ), фильтрованному трехкратно бумажными фильтрами, однократно нутч-фильтром с помощью вакуумного насоса и сушеному в эксикаторе двое суток в объеме 44-50 $\mathrm{cm}^{3}$. Измерения одного и того же масла проводились последовательно друг за другом для того, чтобы выяснить, как изменяется проводимость ТМ с течением времени от начала измерений. Два графика (обозначение 2) соответствуют добавлению в то же ТМ йода $\mathrm{I}_{2}$ до концентрации его в рабочей жидкости порядка $4,97 \times 10^{16} \mathrm{~cm}^{-3}$. Было замечено, что при первых последовательных измерениях масла с йодом при напряженностях до 10-15 кВ/см проводимость растет, а при $E>20$ кВ/см падает. Прово- 


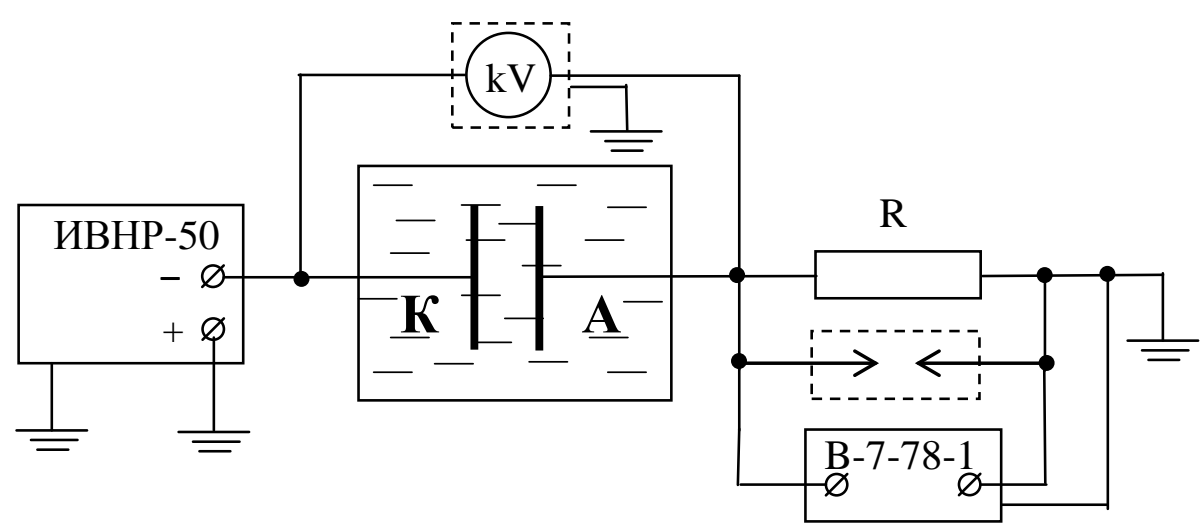

Рис. 6. Схема установки для исследования деградации электродов в высоковольтном режиме.

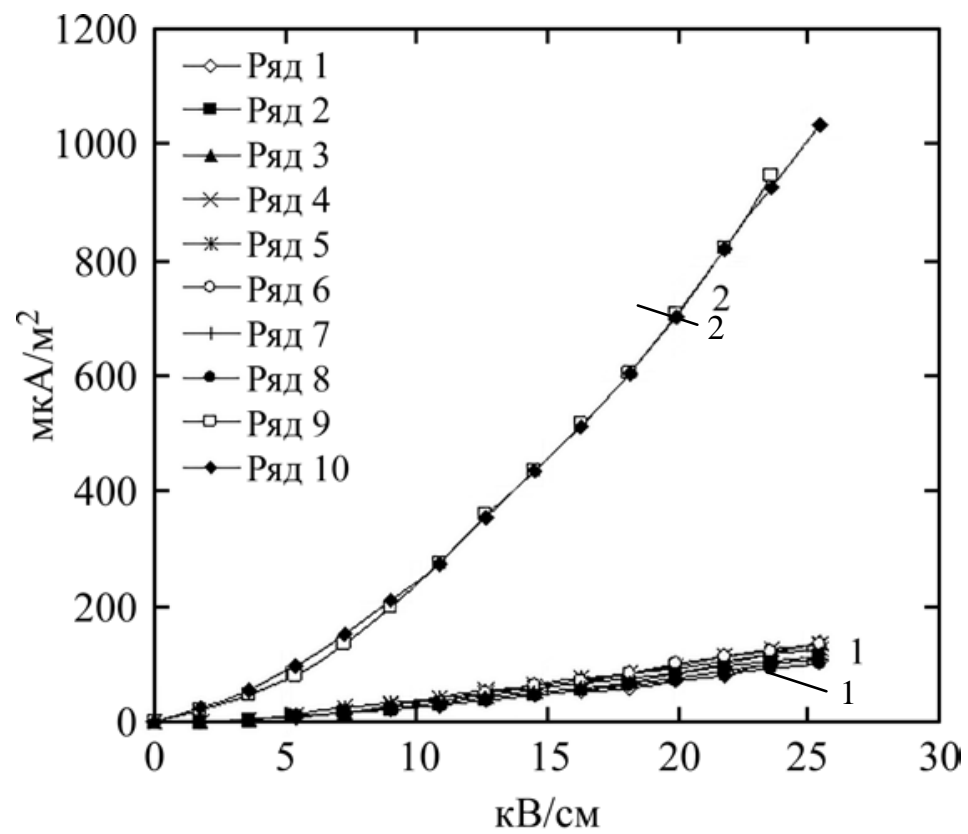

Рис. 7. Вольт-амперные характеристики для: 1 - сушеного двое суток ТМ (ряды 1-8) (Измерения проводились друг за другом. На снятие одной ВАХ затрачивалось около 15 мин); 2 - этого же масла +20 капель раствора йода в ТМ на ячейку (ряды 9, 10) (Концентрация $\mathrm{I}_{2}-4,966 \times 10^{16} \mathrm{~cm}^{-3}$ ).

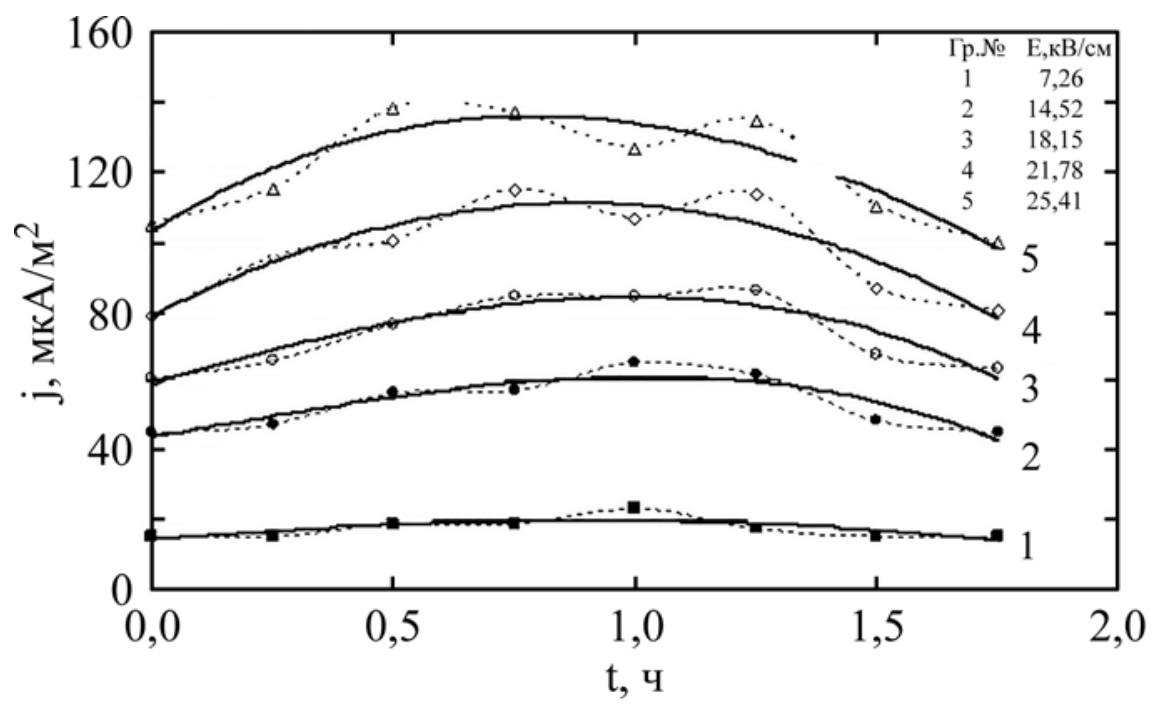

Рис. 8. Ампер-временные зависимости для сушеного двое суток ТМ. Графики аппроксимированы кубическими зависимостями.

димость масла без йода с течением времени, в отличие от масла с йодом, сначала имеет тенденцию к возрастанию по всему диапазону изменения напряженности, а потом возвращается к первоначальному виду. Диапазон изменения электропроводности при этом, измеренный по начальным участкам $\mathrm{BAX}$, соответствует значениям от $\sigma=3,75 \times 10^{-12} \mathrm{Cm} \cdot \mathrm{M}^{-1}$ до $\sigma=5,2 \times 10^{-12} \mathrm{Cm} \cdot \mathrm{m}^{-1}$. На рис. 8 представлены ампер-временные зависимости при разных 


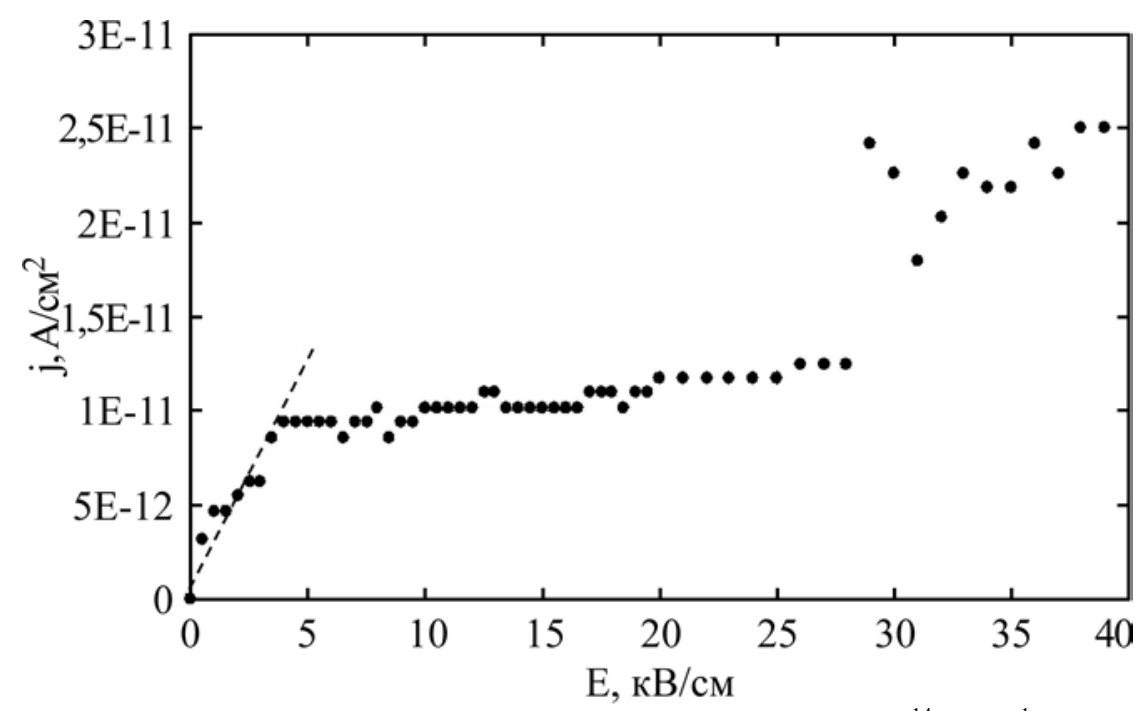

Рис. 9. Ампер-временные зависимости ПМС-50 $\left(\sigma=7,0 \times 10^{-14} \mathrm{CM}^{-1}{ }^{-1}\right)$.

(a)

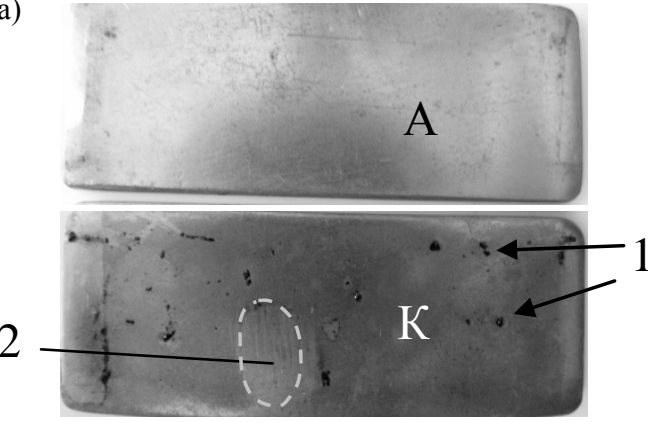

(б)

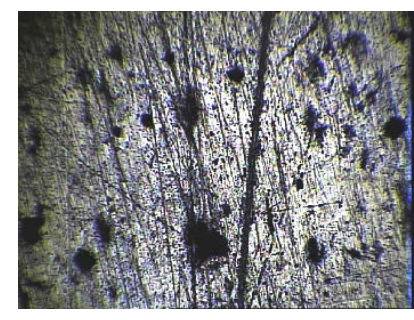

(в)

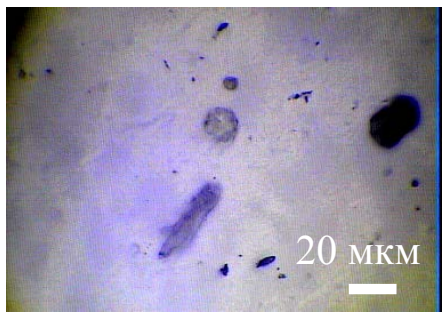

Рис. 10. Поверхность шероховатых Ті электродов после выдержки в растворе ТМ+I при напряженности 20 кВ/см в течение суток (a); $A$ - анод; $K$ - катод; 1 - пятна кристаллического йода; 2 - участок, очищенный от адсорбированного йода; пятна кристаллического йода на дефектах поверхности (б); отложения йода на границах микрокристаллической структуры гладкой поверхности (в).

напряженностях для этого же масла, свидетельствующие о явлении электроочистки, которая проходит в течение более двух часов. Видно, что в области высоких напряженностей с течением времени плотность тока меняется в больших пределах и быстрее достигает максимального значения, чем в низких. В области 25,4 кВ разброс в значениях плотности тока составляет $\sim \quad 40 \%$ от первоначального значения (или конечного). То есть явление электроочистки при высоких напряженностях протекает интенсивней и за более короткое время. При дальнейших последовательных измерениях BAX проводимость практически не меняется.

По-другому ведет себя ВАХ кремнийорганического жидкого диэлектрика ПМС-50 (рис. 9). Плоскопараллельные электроды для измерения BAX установкой (рис. 6) были сдвинуты на расстояние 1 мм. Для ПМС-50 линейный начальный участок простирался до 3,5 кВ/см в отличие от ТМ (чуть выше 1 кВ/см). При дальнейшем росте напряженности наблюдалось плато, при этом на электродах образовывались нитевидные наросты, как будет описано далее, вследствие полимери-зации. Установление большего значения напряженности с определенным шагом приводило по показаниям вольтметра В-7-78-1 к кратковременному ( 3 сек) увеличению тока, а затем ток сбрасывался практически до тех же значений плато. При напряженностях 26-27 кВ/см плотность тока резко возрастала из-за замыкания нитевидными наростами межэлектродного промежутка с возникновением искрения. При этом в области замыкания межэлектродного промежутка возникала, в большей степени выраженная на катоде, темная эрозивная структура, подобная описанным ниже. Анализ токовых характеристик позволил выбрать режим развитой электроконвекции для изучения высоковольтной деградации поверхности электродов со значениями напряженности в межэлектродном промежутке порядка 20-22 кВ/см.

\section{Система Ті электродов в растворах ТМ с йодом $(T M+I)$}

Эксперименты показали, что в $\mathrm{TM}+\mathrm{I}$ электроды из Ті являются индифферентными (не происходят химические реакции с 
(a)

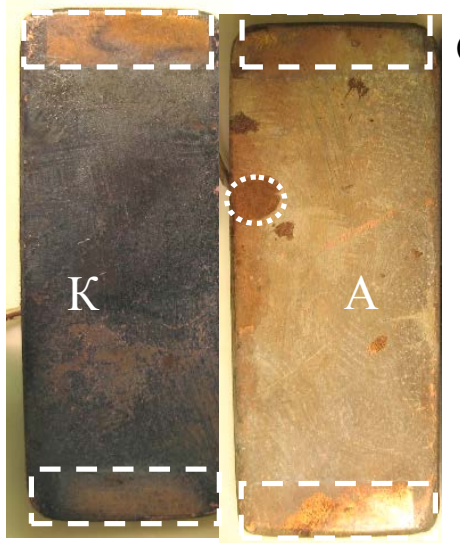

(б)

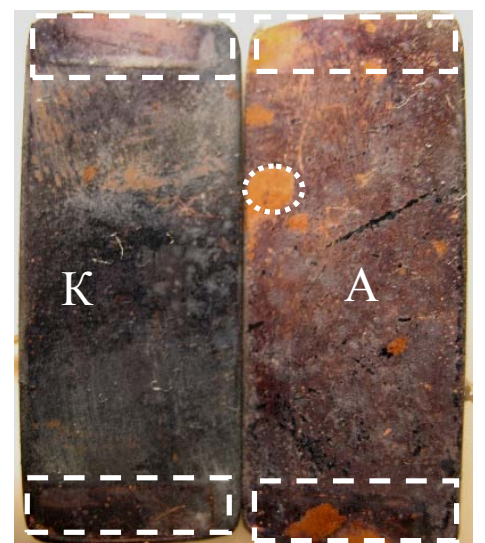

(B)

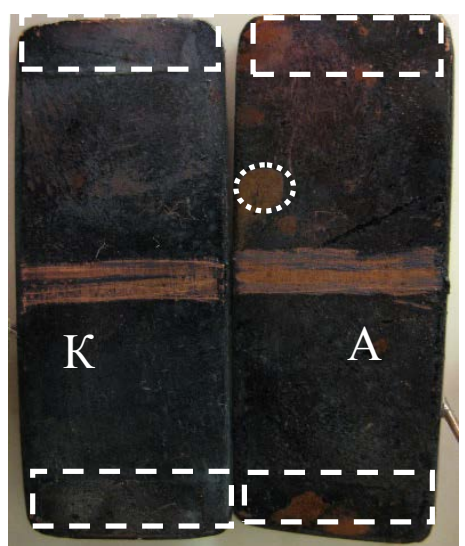

Рис. 11. Изменение медных электродов на аноде (А), катоде (К) во времени: (а) - часы, (б) - дни, (в) - недели при напряженности $20 \mathrm{kB} / \mathrm{cm}$. Оконтуренные участки на торцах суть места крепления электродов, а оконтуренные пятна являются местами неактивных электрохимических процессов.

(a)

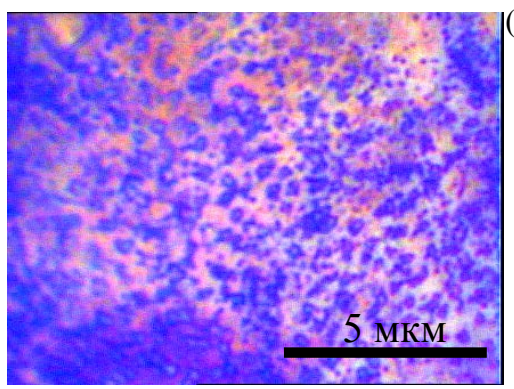

(б)

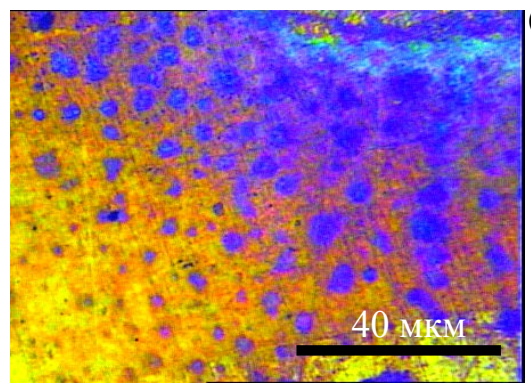

(в)

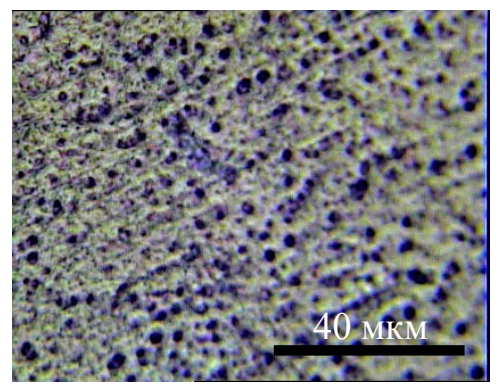

Рис. 12. Эрозивные структуры на аноде (Cu): (а) - в центре электрода; (б) - на крае; (в) - образование пленки с центрами зарядообразования на аноде для ПМС-50 при напряженности 22,8 кВ/см 4 часа.

участием Ті). Однако на их поверхностях заметна физическая адсорбция молекул йода. Причем на катоде и аноде имеются пятна кристаллизации йода, привязанные к царапинам и трещинам на шероховатой поверхности (рис. 10а,б), а также к границам микрокристаллической структуры гладкой поверхности (рис. 10в). Более интенсивно адсорбция происходит на катоде, о чем свидетельствует более темная окраска (рис. 10б).

\section{Система Си электродов в растворах $T M+I$}

Медные электроды деградируют по механизму химической адсорбции (рис. 11). Деградация усиливается с течением времени и проявляется согласно хроматографическому анализу в виде сложных углеводородных соединений с медью и йодом. Так же, как и при Ті электродах, катодные процессы протекают более интенсивно, чем анодные. Это можно объяснить высокой электроотрицательностью молекулярного йода при взаимодействии с поверхностными электронами, образующимися в высоковольтных полях на отрицательно заряженной поверхности металла [12].

По истечении нескольких суток выделения на $\mathrm{Cu}$ электродах чернеют за счет утолщения выделений, а ТМ становится более прозрачным из-за уменьшения объемной концентрации йода.
Это отчетливо видно из рис. 11в, на котором для наглядности удалены выделения в серединной части электродов.

\section{Система Си электродов в ПМС-50}

Характерной особенностью ПМС жидкостей (ПМС-50, ПМС-100, Пента-410) является образование полимерных пленок на Сu электродах за счет электрохимических реакций. На небольших промежутках времени (десятки минут) на обоих электродах формируется пятнистая структура, причем с течением времени пятна растут и сливаются, что приводит к образованию сплошной полимерной пленки с образованием пятен, которые являются местами более интенсивных электрохимических процессов (участками электрохимической инжекции зарядов).

\section{Анод}

На рис. 12 представлены снимки с конфокальной камеры эрозивных структур $\mathrm{Cu}$ анода, получившихся при напряженности между электродами 22,8 кВ/см на чистой ПМС-50. Время выдержки 4 часа. Размер мелких очагов эрозии (рис. 12а) порядка 300 нм. Исследования показали, что к краю электрода (рис. 12б), где электрическое поле возрастает из-за краевых эффектов, структуры уплотняются. 
(a)

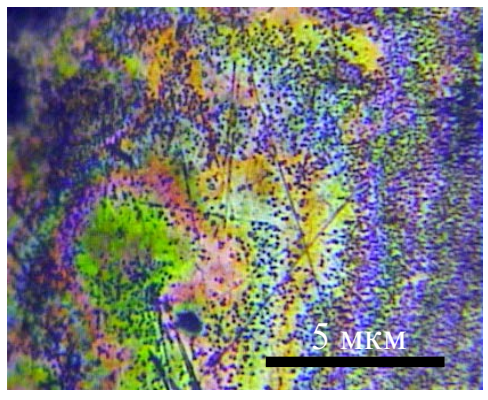

(б)

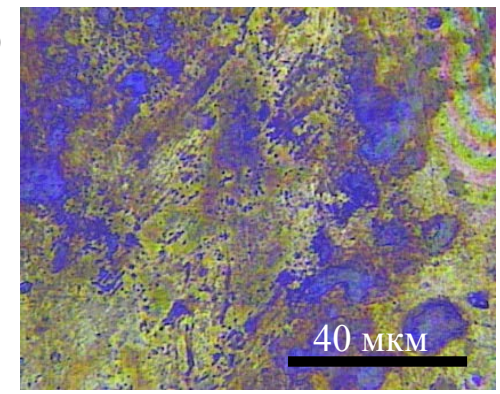

$(\Gamma)$

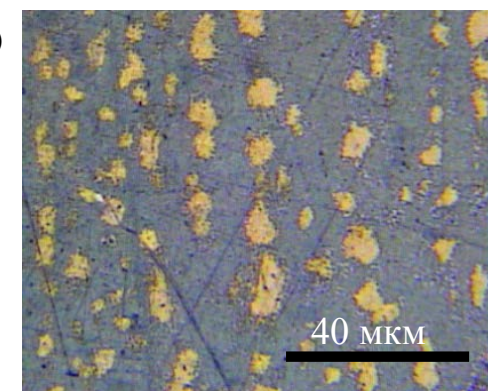

Рис. 13. Характерные эрозивные структуры на катоде (Cu): (a) - плотные мелкие структуры; (б) - сочетание мелких и крупных; (в) - крупные структуры; (г) - электрохимические отложения в отсутствие эрозии. (Чистая ПМС-50, при $E \sim 22,8$ кВ/см и 4 часах электроконвекции).
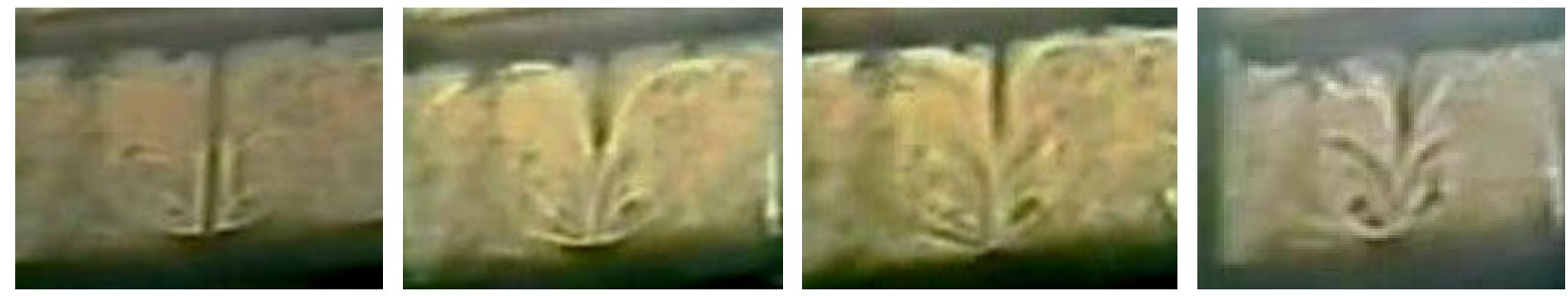

Рис. 14. Последовательные кадры развития ЭГД-течения в ПМС-50 в системе электродов лезвие-плоскость (теневые изображения).

\section{Kamod}

Поверхность катода представлена большим разнообразием новообразований на поверхности, обусловленных не только электрохимическими процессами, но и электроконвективным перераспределением реагентов (рис. 13). При тех же напряженностях электрического поля наблюдаются участки более плотного расположения мелких $\sim 300$ нм эрозивных структур (рис. 13a), участки с сочетанием мелких и крупных областей эрозии (рис. 13б) и обособленных крупных образований различной формы (рис. 13в), а также участки отложений продуктов электрохимических реакций (рис. 13г).

Причины появления таких структур можно объяснить интенсификацией электрохимических процессов с участием $\mathrm{Cu}$ и ПМС-50 на дислокационных границах поликристаллической структуры $\mathrm{Cu}$ электрода.

Объемная полимеризащия ПМС-50 в электродной системе лезвие-плоскость

В сильно неоднородных высоковольтных полях имеет место объемная полимеризация ПМС-50, которая отчетливо наблюдается на теневых снимках в электродной системе лезвие- плоскость (рис. 14). Полимеризация более интенсивно происходит в окрестности острийкового электрода. Механизм полимеризации можно объяснить тем, что образующиеся заряды на поверхности острийкового электрода катализируют концы ПМС молекул - $\left[-0-\mathrm{Si}-\left(\mathrm{CH}_{3}\right)_{2}\right]_{\mathrm{n}}-$, что приводит к их удлинению, то есть к полимеризации.

\section{Система Си электродов в ПМС-50+I}

Добавление йода с концентрацией $1,79 \times 10^{18} \mathrm{~cm}^{-3}$ в ПМС-50 привело к резкому увеличению проводимости и, как следствие, к появлению непрерывной серии пробоев при напряженности $20 \mathrm{\kappa B} / \mathrm{cm}$. Пробои прекращались при уменьшении максимальной напряженности до 14 кВ/см. На поверхностях анода и катода выделяются продукты электрохимических реакций в виде неоднородных пленок, а на катоде дополнительно обнаружены участки кристаллизации йода.

\section{Анод}

На рис. 15 показаны участки поверхности анода 1, 2 и 3 через 15 минут в ПМС-50 + I 2 при 

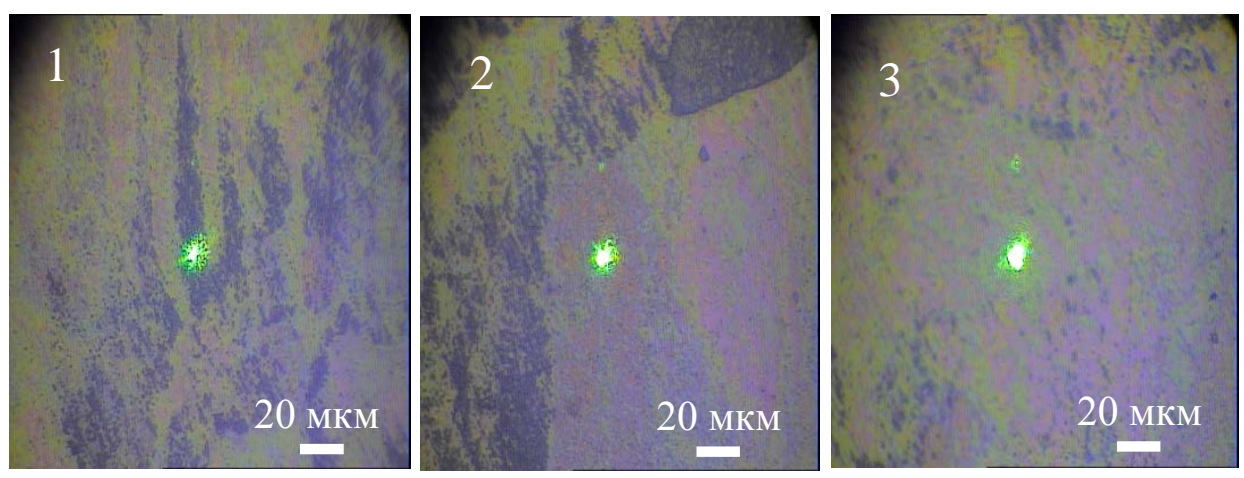

Рис. 15. Участки поверхности анода через 15 минут после включения напряжения в ПМС-50 + $\mathrm{I}_{2}$ при напряженности 22,8 кВ/см. Светлые точки на участках 1, 2 и 3 являются областями снятия КР-спектров.

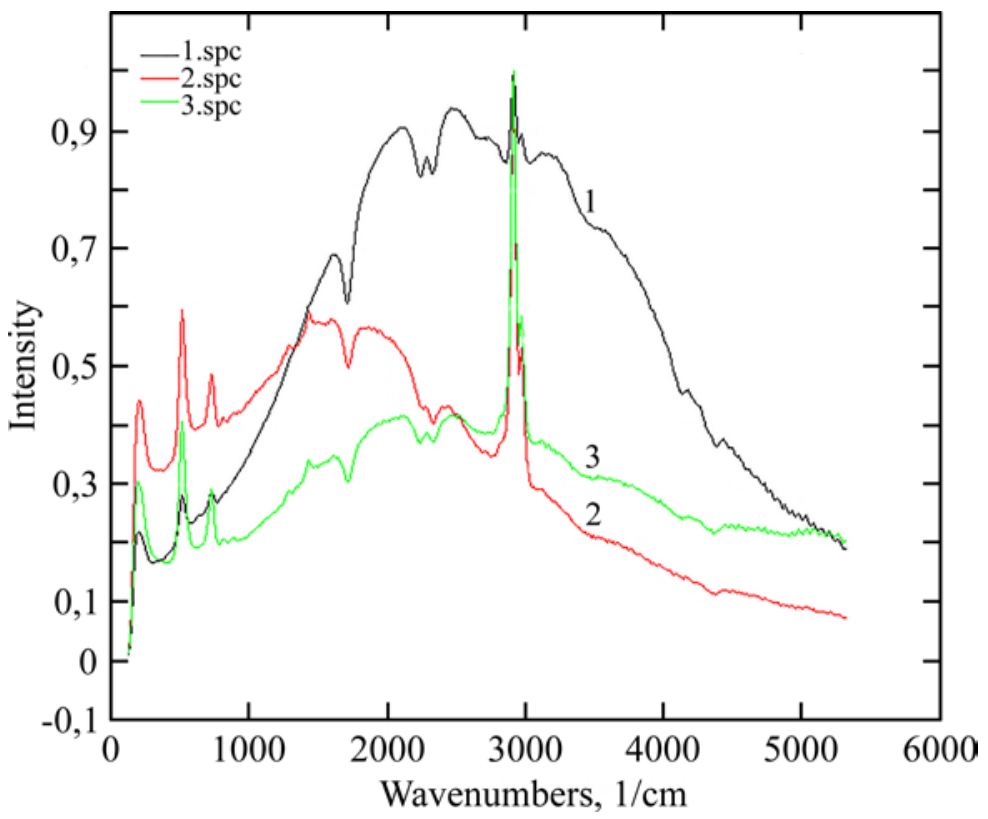

Рис. 16. КР-спектры светлых центральных участков 1, 2, 3 с рис. 12.

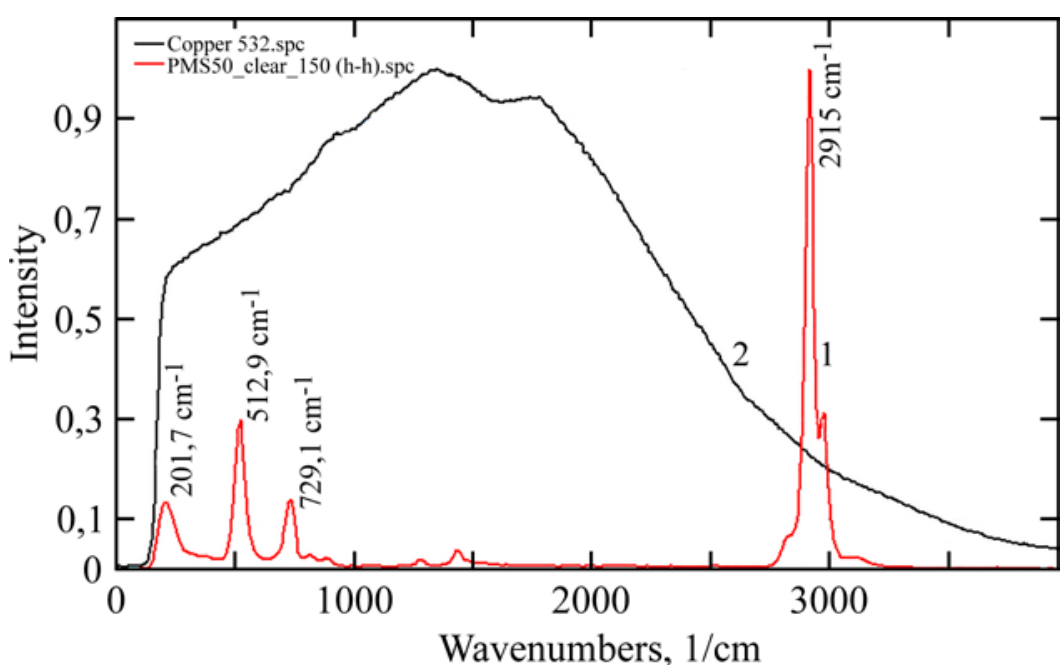

Рис. 17. КР-спектры на частоте 532 нм: 1 - на чистой жидкости ПМС-50; 2 - на поверхности медного электрода.

напряженности 22,8 кВ/см, а на рис. 16 представлены их комбинационные спектры на возбуждающей частоте 532 нм, снятые в светлых точках в центре фото. Острые пики на спектрах соответствуют спектру чистой ПМС-50 (см. рис. 17) с характерными пиками деформационных и валентных колебаний $\left(\mathrm{cm}^{-1}\right)$ : 201,7, 512,9, 729,1, 2915,0. Плавные участки спектров на рис. 16 соответствуют спектру поверхности медного электрода с адсорбированными на поверхности продуктами реакций. По интенсивности пиков можно заметить, что в спектре 1 (рис. 16), снятом в темной области, наблюдается меньшее количество ПМС-50, чем в спектрах 2 и 3. Можно предположить, что на темных участках поверхности происходит более интенсивное зарядообразование. 

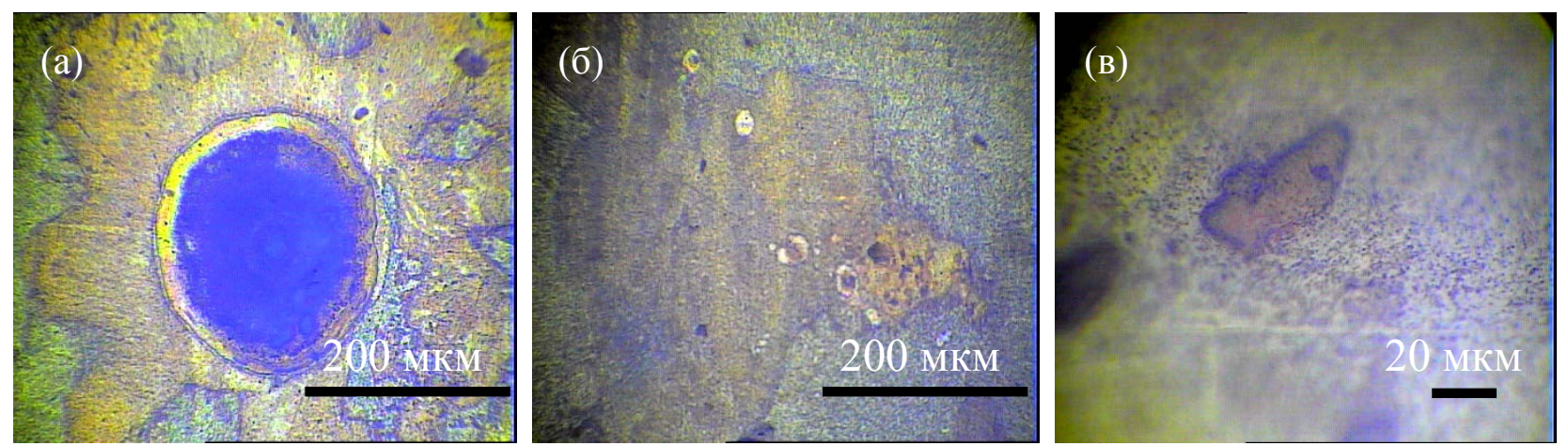

Рис. 18. Области полимеризации на катоде $\left(П М С-50+\mathrm{J}_{2}\right)$ : (а) - полимеризационная область вокруг эрозивного пятна; (б) - в области пробоев; (в) - полимеризационный островок.
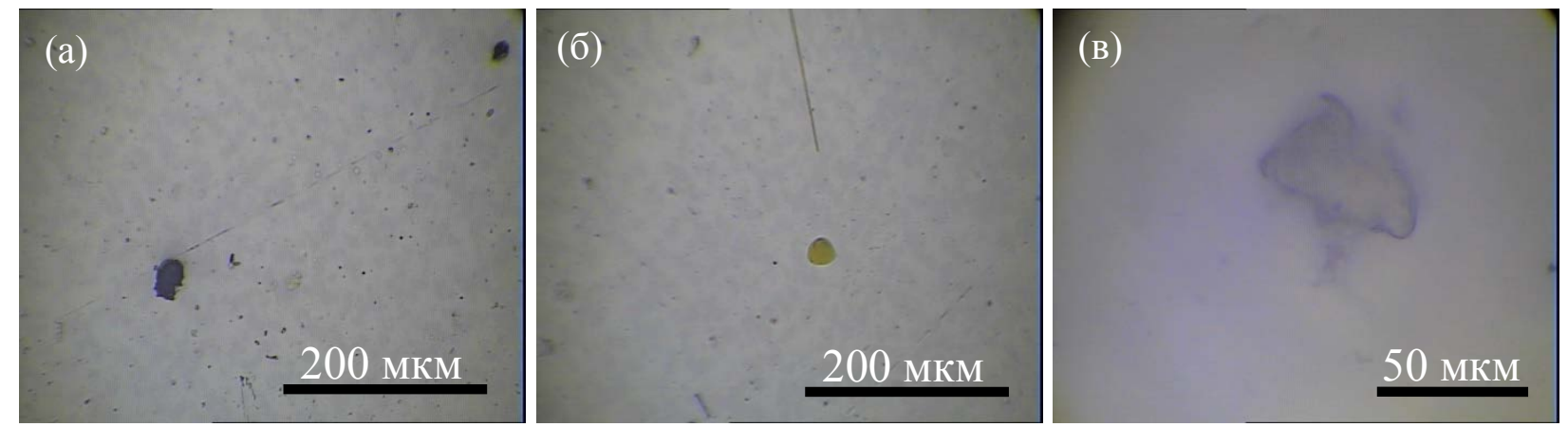

Рис. 19. Образования на поверхности катода из Ті после электроконвекции в ПМС-50 + I: (а) - область адсорбции йода; (б) - полимеризация в виде кластера; (в) - область полимеризации.

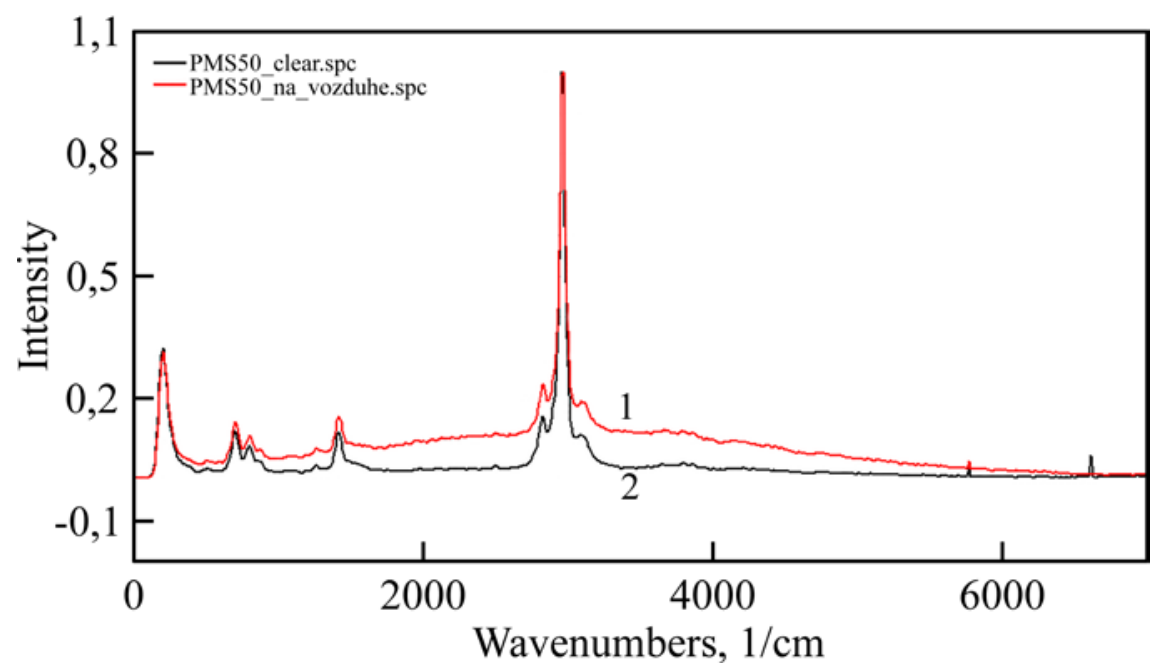

Рис. 20. КР-спектры чистой ПМС-50 и раствора ПМС-50 с йодом, выдержанного в течение нескольких суток с открытой поверхностью на воздухе.

\section{Kamod}

При напряженности 22,8 кВ/см в течение 15 минут на катоде образуются полимерные пленки c круговыми пятнами выделения йода (рис. 18a,б). С течением времени (порядка 30 мин) размер пятен увеличивается и четко выделяется полимеризационная граница с полимерной пленкой, на которой видны участки кристаллитов меди (рис. 18в). Постепенно раствор ПМС-50+I при электроконвекции становится более светлым, что свидетельствует об уменьшении концентрации йода вследствие его адсорбции на электродах.

\section{Система Ті электродов в ПМС-50+I}

$\mathrm{Ha} \mathrm{Ti}$ электродах в отличие от $\mathrm{Cu}$ наблюдается незначительное количество выделений на полированных электродах. Это объясняется, с одной стороны, меньшим количеством дефектов (раковин, царапин), с другой - индифферентностью титана. На поверхностях Ті анода и катода областей эрозии не наблюдается, но видны редкие области адсорбции йода как на аноде, так и на катоде (рис. 19) и малое количество выделений продуктов полимеризации и разложения жидкости. 
Исследования на рамановском микроспектрометре показали, что чистая жидкость ПМС-50 и ПМС-50 с йодом, как в электрическом поле, так и в течение недели контактировавшая открытой поверхностью с воздухом, дают один и тот же спектр комбинационного рассеяния (КР-спектр) (рис. 20).

При контакте с воздухом фиолетовый оттенок ПМС-50+I исчезает, что говорит о возгонке йода в воздух вследствие отсутствия прочных химических связей молекул ПМС с йодом (в отличие от ТМ). Это является доказательством стабильности и химической устойчивости ПМС-50.

\section{ВЫВОДЫ}

1) Высоковольтная электроконвекция в углеводородных и кремнийорганических жидкостях приводит к развитию множества типов адсорбированных структур, образующихся на поверхности электродов, полированных до качества 20 нм, как на аноде, так и на катоде. Их образование определяется как качеством поверхности (адсорбционными центрами, дефектами), так и характеристиками жидкости и примесными добавками.

2) В углеводородах $\mathrm{Cu}$ электроды интенсивно взаимодействуют с $\mathrm{I}_{2}$, причем катодная деградация более интенсивная, чем анодная. В ПМС-50 на $\mathrm{Cu}$ электродах обнаружено интенсивное образование полимеризовавшейся пленки как на катоде, так и на аноде, с микроскопическими порами в областях инжекции зарядов с поверхности электродов, через которые протекает микроконвекция.

3) Основные эрозивные структуры возникают в первые 10 минут при напряженности поля 20 кВ/см. Далее по времени новых эрозивных очагов не возникает, а ЭК сопровождается незначительным ростом уже присутствовавших.

4) Ті электроды не деградируют, но на них в углеводородах происходит физическая адсорбция $\mathrm{I}_{2}$. На $\mathrm{Ti}$ электродах в отличие от $\mathrm{Cu}$ наблюдаются незначительное количество выделений на полированных электродах и редкое островковое появление полимеризации. Это объясняется, с одной стороны, меньшим количеством дефектов (раковин, царапин), но в основном индифферентностью титана.

5) КР-спектры в центрах всех эрозивных структур на поверхности $\mathrm{Cu}$ показывают малое количество рабочей жидкости, что говорит об отсутствии смачивания жидкостью и диффузионного слоя в этих областях зарядообразования при конвекции.

6) Полимеризация ПМС жидкостей на электродах и инжектирующая добавка на основе молекулярного йода при использовании метал- лических электродов приводят к ограниченному ресурсу работы ЭГД систем в силу электрохимических реакций и адсорбционных процессов. Ресурс работы ЭГД устройств можно повысить, используя индифферентные электроды либо специальные покрытия на электродах, препятствующие прохождению электрохимических реакций и снижающих адсорбцию на электродах.

\section{ФИНАНСИРОВАНИЕ}

Работа выполнена при поддержке Министерства образования и науки Российской Федерации в рамках госзадания № 0851-2020-0035.

\section{КОНФЛИКТ ИНТЕРЕСОВ}

Авторы заявляют, что у них нет конфликта интересов.

\section{ЛИТЕРАТУРА}

1. Сканави, Г.И., Физика диэлектриков: область слабых полей. М.: Физматгиз, 1949. 500 с.

2. Сканави, Г.И., Физика диэлектриков: область сильных полей. М.: Физматгиз, $1958.907 \mathrm{c}$.

3. Адамчевский, И., Электрическая проводимость жидких диэлектриков. Л.: Энергия, 1972. 149 с.

4. Семенченко, В., Физическая химия растворов. М.-Л.: Гостехиздат, 1941. 344 с.

5. Onsager, L.J., Deviation from Ohm's Law in Weak Electrolytes, Chem. Phys., 1934, no. 2, p. 599.

6. Киреев, В.А., Курс физической химии. М.: Химия, $1975.775 \mathrm{c}$.

7. Измайлов, Н.А., Электрохимия растворов. М.: Химия, $1976.575 \mathrm{c}$.

8. Жакин, А.И., Электрогидродинамика многокомпонентных диэлектрических жидкостей, Вестник ХГУ. Математика, механика и вопросы управления, 1983, т. 241, с. 3.

9. Zhakin, A.I., Electrohydrodynamics, CISM Courses and Lectures. № 380. Undine, Italy, 1998. 363 p.

10. Zhakin, A.I., Electrohydrodynamics: Basic Concepts, Problems and Applications, Kursk: University press, 1998. $132 \mathrm{p}$.

11. Жакин, А.И., Ионная электропроводность и комплексообразование в жидких диэлектриках, УФН, 2003, т. 173, № 1, с. 51 .

12. Жакин, А.И., Приэлектродные и переходные процессы в жидких диэлектриках, УФН., 2006, т. 186, № 3, c. 289 .

13. Жакин, А.И., Электрогидродинамика, УФН., 2012, т. 182 , № 5 , с. 495 .

14. Жакин, А.И., Кинетика агрегирования в неполярных жидких диэлектриках, ЭОМ, 2015, т. 51 , № 4, с. 49 . 
15. Жакин, А.И., Редокс-системы в электрогидродинамике и расчет электроконвективных течений, Магнитная гидродинамика, 1982, № 2, c. 70 .

16. Федоненко, А.И., Жакин, А.И., Экспериментальные исследования электроконвективного движения в трансформаторном масле, Магнитная гидродинамика, 1982, № 3, с. 74.

17. Болога, М.К., Гросу, Ф.П., Кожухарь, И.А., Электроконвекция $u$ теплообмен. Кишинев: Штиинца, 1977.320 с.

18. Стишков, Ю.К., Остапенко, А.А., Электрогидродинамические течения в жидких диэлектриках. Ленинград: ЛГУ, 1989. 174 с.

19. Стишков, Ю.К., Чирков, В.А., Моделирование структуры электрогидродинамических течений в несимметричной системе электродов, ЖТФ, 2005, т. 75 , № 5 , с. 46 .

20. Жакин, А.И., Кузько, А.Е., Электрогидродинамические течения и теплообмен в системе электродов лезвие-плоскость, Известия РАН. Механика жидкости и газа, 2013, № 3, с. 31.

21. Штерн, Е.Н., Могилева, Е.С., Особенности воздействия поля постоянного напряжения на жидкие нефтяные диэлектрики, Электротехника, 1980, № 6, с. 50.

22. Wang, Z., Yi, X., Huang, J., Hinshaw, J., et al., Fault gas generation in natural-ester fluid under localized thermal faults, IEEE Electr. Insul. Mag., 2012, vol. 28, no. 6, p. 45.

23. Липштейн, Р.А., Шахнович, М.И., Трансформаторное масло. М.: Энергоатомиздат, 1983. $296 \mathrm{c.}$

24. Jovalekic, M., Vukovic, D. and Tenbohlen, S., Dissolved gas analysis of alternative dielectric fluids under thermal and electrical stress, IEEE International Conference on Dielectric Liquids, 2011, p. 1-4. doi: 10.1109/ICDL.2011.6015457

25. Казарновский, Д.М., Яманов, С.А., Радиотехнические материаль. М.: Высшая школа, 1972. $312 \mathrm{c}$.

26. Walvekar, R., Zairin, D.A., Khalid, M., Jagadish, P., et al., Stability, thermo-physical and electrical properties of naphthenic/POME blended transformer oil nanofluids, Therm. Sci. Eng. Prog., 2021, vol. 23, 100878.

27. Amiri, A., Kazi, S.N., Shanbedi, M., Mohd Zubir, M.N., et al., Transformer oil based multiwalled carbon nanotube-hexylamine coolant with optimized electrical, thermal and rheological enhancements, RSC Adv., 2015, no. 130, 107222.

28. Beheshti, A., Shanbedi, M., Heris, S.Z., Heat transfer and rheological properties of transformer oil-oxidized MWCNT nanofluid, J. Therm. Anal. Calorim., 2014, vol. 118, no. 3, p. 1451.

29. Liu, M., Yang, Q. and Wu, S., Space charge injection behaviors and dielectric characteristics of nanomodified transformer oil using different surface condition electrodes, AIP Adv., 2019, vol. 9, no. 3, p. 035319.

30. Wu, S., Yang, Q., Shao, T., Zhang, Z., et al., Effect of surface modification of electrodes on charge injection and dielectric characteristics of propylene carbonate, High Voltage, 2020, vol. 5, no. 1, p. 15.

31. Russel, M., Selvaganapathy, P. and Ching, C., Effect of electrode surface topology on charge injection characteristics in dielectric liquids: an experimental study, J. Electrostat., 2014, vol. 72, no. 6, p. 487.

32. Гороновский, И.Т., Назаренко, Ю.П., Некряч, Е.Ф., Краткий справочник по химии. Киев: Наукова думка, 1987, 833 с.

\section{Summary}

The results of experimental studies of the electrode degradation caused by electrochemical reactions under the action of high-voltage fields are presented. Under study were technical hydrocarbon and polymethylsiloxane (PMS) liquids, their solutions with iodine $\left(\mathrm{I}_{2}\right)$ at chemically active $(\mathrm{Cu})$ and indifferent $(\mathrm{Ti})$ electrodes. It is shown that in hydrocarbons the $\mathrm{Cu}$ electrodes interact intensively with $\mathrm{I}_{2}$, and the cathodic degradation is more intense than the anodic one. The Ti electrodes do not degrade, but physical adsorption of $\mathrm{I}_{2}$ occurs on them in hydrocarbons, and a polymer film forms on them in PMS. The kinetics of degradation in time was studied.

Keywords: ion, dipole, polarization, dielectric constant, liquid dielectric, electric field, intensity, electric current, electrochemical reaction, charge injection, electrode degradation 